\title{
Management of, Knowledge, Information and Organizational Learning in University Libraries
}

\author{
LuIS AHUMAdA FigueroA AND AtiLIO Bustos GONZÁLEZ \\ Pontificia Universidad Católica de Valparaíso, Valparaíso, Chile
}

The dynamic advancement of technological development and the importance of information and knowledge in modern-day society have determined that the principal competitive advantage of an organization is the capacity to manage these resources adequately. The abilities and knowledge that workers are capable of developing are transformed into a resource that modern organizations value in a growing way. Educational organizations, especially universities, must take advantage of their competitive resources. That is to say, they must know how to make intensive use of their knowledge in order to improve: the process of formation and learning of their students, the generation of new knowledge produced by research and the transference of said knowledge by means of publication and technical assistance. The processes of management of knowledge, organizational learning and information are intimately linked. Therefore, significant improvements can only be obtained in organizations if syner-

\section{Introduction}

\section{Present context of University Libraries}

Constant environmental change imposes information and action requirements on university organizations with the goal of achieving better adaptation (Levine 2002; Teare et al. 2002). Fluctuations in the economy, technological innovations, legal reforms, the increasing specialization of the work force, work flexibility and the flattening of organizational structure are factors that are cited with frequency as examples of environmental changes (Sisto 2002; Barkema et al. 2002). In this context, the gies are generated between each one of these processes. In order to study these three processes, the Universities' Library Systems of the Pontificia Universidad Católica de Valparaíso were selected as a unit of analysis, and considered as places of knowledge gathering, documentation centres and active agents in the development of abilities in the use and transference of information necessary to generate new learning and knowledge. The principal objective of this investigation was to characterize the management of information, knowledge and organizational learning in a university's library system, analysing its relationship and the way that these processes differ depending on variables such as department membership, the characteristics of users that rely on them, etc. The efficient management of organizational learning implies not only the utilization of previous knowledge but also the creation of new knowledge within the framework of what are termed communities of learning.

Dr. Luis Ahumada F. is Professor of Organizational Development and Knowledge Management in the School of Psychology, Pontificia Universidad Católica de Valparaíso, Valparaíso, Chile. E-mail: lahumada@ucv.cl

Mg. Atilio Bustos G. is Director of Library System of Pontificia Universidad Católica de Valparaíso, Valparaíso, Chile. E -mail: abustos@ucv.cl 
The University, from this perspective, must take advantage of its competitive resources. It must make intensive use of its knowledge with the goal of improving the development of its students and its strengths as an organization (Herrera 1998; Lindauer 1998). These processes are registered in what is called the management of organizational knowledge (Brockmann and Anthony 2002; Fiol 2002; Hatch and Schultz 2002). Vignolo (1998) points out that the management of knowledge drives the organization to obtain penetration (knowledge of its external environment) and to understand its own experience (knowledge of its internal environment). In other words, it allows the generation and utilization of spaces of interaction; the development of intangible assets that support an organization in the achievement of its goals (Mamaghani 2002).

Thus, an efficient management of information, knowledge, and organizational learning appears as the principal source of competitiveness. In fact, the knowledge that an organization possesses is the product of a complex social structure, difficult to comprehend, imitate or internalise by competitors and, therefore, in it lays the principal advantage of the organization (Edwards and Mercer 1998; Tsoukas and Chia 2002; Argote et al. 2003).

In this sense, universities' libraries play a fundamental role by providing students, teachers and investigators with the means and resources to go about discovering and constructing knowledge (Duart and Sangrà 2000). Also, the workers of these libraries acquire the function of guides in the sense that they support the development of those competencies that allow a more effective and significant utilization of the information and knowledge available (Akeroid 2001; Teare et al. 2002). Vergara and Isaac (1998) point out in this respect that the competencies that almost all workers need in the job include abilities to:

1. acquire and evaluate information

2. organize and maintain information

3. interpret and communicate information

4. use computers to process information

The present context of organizations, and in particular of universities, raises the necessity of research into how the management of information, knowledge and organizational learning is articulated in institutions of higher education. It is of especial interest to study university libraries given their characteristics as places of focusing and forming abilities with respect to the use and transference of the information necessary to generate learning and knowledge.

\section{University Libraries: knowledge management, learning management and management of information}

The major part of studies on the efficacy and the quality of university libraries never adopts a global, institutional view when they relate the library programmes with the results of the institution (Cave et al. 1997; Lindauer 1998). In contrast, as Lindauer (1998) points out, they have concentrated primarily on measuring and evaluating quantity, efficacy/quality and efficiency of traditional resources of university libraries (personnel, budgets, collections, installations and equipment), of the processes (development of collection, cataloguing, management methods), and of the products (reference service, use of automated catalogue, interlibrary loan and document access). One very common observation in numerous publications is that what is most needed are indicators of performance that demonstrate the impact of the university library on the desired educational results and the corresponding methods to measure them (International Organization for Standardization, 2000). For Lindauer (1998), the determining factors of the quality of a library must be linked to educational results. However, there is a lack of objective methods to measure and incorporate the value of the library in processes such as those of accreditation and educational evaluation.

In our judgement, the quality of the services offered by university libraries is derived necessarily from the management of three aspects already mentioned, namely: information, knowledge and organizational learning. The quality of these services will therefore be an indicator of the level of the efficiency achieved in 
these substantive components, as well as the synergy that is achieved with the integration of the three functions within a single system.

University libraries can be understood as generators of knowledge, where this is transformed into learning and stays registered as information. This knowledge is generated by faculty members in their study and research process with the support of the library, as well as by library staff in the process of improving the quality of support services. For this reason, the academic library achieves one of its major goals when its users make more efficient management of information and knowledge

From the point of view of management of information, the function of university libraries consists in positioning their users in the main stream of their disciplines. From the knowledge management point of view, the university libraries must provide visibility to the knowledge produced by their Universities, exhibited through their publications in document repositories and the publishing of journals and monographs from the knowledge produced. Libraries and centres of documentation have always played an important role in the development of learning, teaching and research; but the change they have experienced produced by the intensive use of information technologies and communications (Bustos 1996; Harasim et al. 2000) has transformed these centres into basic axes of a model designed to exercise the educational and research function in a virtual environment (Pérez 2000), increasing the need for efficient knowledge management.

The assumption that guided this research study is that the processes of the management of information, knowledge and organizational learning are intimately related, in such a way that developing these processes in an integrated way generates growing returns for the organization. Thus, the research proposal consisted of the description of these processes in a System of University Libraries.

\section{Methods}

In order to achieve the objective previously indicated a qualitative methodology was utilized. Exploratory descriptive research was developed, with the aim of testing the degree of relationship existing between the management of information, of knowledge and of organizational learning in university libraries. The investigation was carried out in the University Libraries of the Pontificia Universidad Católica de Valparaíso. The sample consisted of four faculty libraries (Basic Sciences, Educational Sciences, Engineering, and Ocean Sciences). The participants were the staff members and heads of the selected libraries.

The qualitative data collection was oriented to discover, capture and understand the significance that springs from the symbolic interaction between individuals. This methodology aimed to capture all of the experiences and the meaning of the social actors in a determined situation (Ruiz 1996). The following techniques were used to gather information:

1. Study of the "files" of the organization: a series of documents of the organization were examined such as mission, vision, organizational charts, development projects, strategic plans and job descriptions. Likewise, significant documentation of the organization that constitutes part of its operational history was analysed (statutes, internal regulations, resolutions, etc.).

2. In-depth interviews: a series of in-depth interviews was carried out with staff and heads of the Library System. The potentials and weaknesses of the organization were analysed in these interviews, as well as those aspects that, in the opinion of those interviewed, facilitate or hinder knowledge management in the organization.

In respect to the processing and analysis of the obtained data related to information management, the management of organizational learning and the management of knowledge, approaches to discourse analysis proposed by the following authors were utilized: Potter and Wetherell (1987), Halliday (1994), Chia (2000), Van Dijk (2000), and Renkema (2001).

The proposal by Renkema (2001) was especially useful for the analysis of documents. The CCC model proposed is based on the criteria of correspondence, consistency, and correction. These criteria intersect with the five levels that can be distinguished in the analysis of texts, namely: textual type, content, structure, writing and presentation, the first three being especially relevant to the analysis of institutional 
documents (Renkema 2001).

In the analysis of the accounts of the participants in the process of knowledge management in the libraries analysed, the model proposed by Van Dijk (2000) was followed with the objective of realizing the different nuances of the implicit discourse in these texts, especially in reference to his conception of power and change. The study particularly focused on the superstructural levels (types of discourse) and macrostructural (themes) which these texts presented. Halliday (1994) contributed a vision of the narrations of the actors that linked their discursive clauses with the context where these narrations operate. This becomes relevant when analysing the social management of knowledge as a process of interaction.

The analysis of the discourse in the pragmatic approach of Potter and Wetherell (1987) precisely penetrates that relational complexity. Words and concepts acquire their meaning in the social context in which interactions take place. In this perspective, the social functions of the language are analyzed in terms of driving or stopping determinate interactions or interpretations of the reality. The analysis of the use of language in the libraries studied allows a better understanding of the social relations that take place in the different learning communities and the meaning associated with efficient knowledge management.

\section{Results}

The following is a presentation of the main results obtained from carrying out the methodology previously described in each one of the dimensions studied.

\section{Information Management in the University Libraries}

The results of the present research show that the management of information must be based in the information requirements or needs of the users of the system or service. Therefore, the management of information must necessarily start with the identification of information needs and the profile of a system's users, transforming this into a permanent activity given the changing character of its needs.

In the following we will give some textual quotations from our interviews and comment upon these extracts from the staff members and heads of the sample libraries.

\footnotetext{
"In our library we maintain up to date statistics of use of information resources. This allows us to have an idea of the requirements of the user, however, it is necessary to know how to detect necessities, to evaluate periodically what is useful and what is not." (Basic Sciences)

"we give the information to each particular user because each user of each faculty is different, but there also exists a difference according to status, as students require different information resources than professors" (Engineering)
}

"the profiles that they have achieved have been exactly according to their needs, having to choose things that are very precise for them," (Ocean Sciences)

The System of Libraries studied has made significant efforts to move the sources of information closer to the user, enabling the user to access information from his own place of work (office, home, classroom, learning laboratory, etc.) At the same time, the development of a "Virtual Library" in terms of available bibliographic resources (e.g. electronic journals, alert services, information contained on websites, etc.), combined with this new utilization of virtual spaces, has contributed to a better management of information on the part of all of the users.

\footnotetext{
"the spaces are virtual; now there are no time barriers. Because the subject of communications allows it to be that way, that there is permanent communication...that there exists contact albeit virtual between people." (Basic Sciences)

"On a day to day basis, we are involved in the management of information, providing access to it, managing all that our students and researchers need" (Engineering)

\begin{abstract}
"Before, obtaining an article was very complicated, whereas today it is available in 24 hours. The professor has the information that she needs for her research; I think it is fundamentally everything that the Internet has provided" (Ocean Sciences)
\end{abstract}

In this context, it is necessary that the users know how to take adequate advantage of all the resources that the libraries offer them. Therefore, 
the work of "training" the users on the part of the University Libraries' staff is of vital importance for improving their abilities in searching for and managing information.

\begin{abstract}
"They know what their needs are, but they do not always know how to reach the information that they really need. Thus, this is the function, the mission in which we are involved now." (Basic Sciences)

"to be in this area, hand in hand with professors, implies that we develop together with them a part of the class. This is a characteristic that brings with it the development of the ability of information literacy." (Engineering)

"despite the fact that there is an open shelf and that electronic catalogues exist, when the student arrives from high school he comes with a lot of ignorance in respect to what is the university; thus, here we have to assimilate him. This is the first step that we must carry out with first-year students" (Ocean Sciences)
\end{abstract}

In this sense a change of orientation has been produced, from the quality of service to the quality of in-formation where the emphasis is placed as much on the availability of necessary information resources as on adequate training in order to have access to information. The developmental role of the personnel of the libraries studied has transformed their jobs as librarians, by introducing new teaching functions. This role change is due to the effects of new information technologies on higher education and the need to acquire the capabilities of information access and use.

\section{Management of knowledge in the University Libraries}

The results of our study show that this process takes places within a learning community, where knowledge is created and expanded in a dynamic constant between the unspoken and the explicit.

"Everything is related in research material. This now belongs to the world, because all of the world has access to it. There is no sense in research staying in a desk to later become a book or for it to be kept saved." (Basic Sciences)

"what we want is to introduce to the student and to professors information literacy standards." (Engineering)

"from the moment that all teaching, study plans, and the program structure changed, the change has exploded everywhere and not only in the library. This has made professors look at teaching and the classroom in another light..., since now the classroom is not the place where students are writing and the professor is at the blackboard; the classroom is something else, it is something dynamic" (Ocean Sciences)

These communities of learning are emerging communities; that is, they are not deliberately created by an external agent in order to develop a specific activity, but they arise from the same activity as a way of giving response to the daily problems that are being presented to the said community.

"I like discussing with them although in a trivial way and I think that the fact of not waiting for them to come to me has opened for me a great space within the Department. I go to them and they value that." (Engineering)

"several of us within the system have had the experience of participating in courses and seminars where we have a relationship with determined people. We have been given other opportunities to be in contact with professors where we are learning something in common... instances of finding and situations of mutual learning" (Basic Sciences)

"the human part is fundamental, being with them,... then you become involved in their area..." (Ocean Sciences)

These learning communities are where all of these abilities are learned. These permit the location, recovery, evaluation, production and presentation of information, with the aim of transforming information into knowledge. The management of knowledge goes beyond the management of information, given that the management of knowledge implies an integration of the management of information in significant units and with a new meaning, where the use of language plays a fundamental role.

\section{Management of organizational learning in University Libraries}

In the development of a university library that is integrated and coherent with the global objectives of the University, it is necessary to bear in mind individual learning as well as organizational learning. The learning of staff members of the System of Libraries studied here is an individual learning process but one that in the end has an enormous impact on organizational learning. The major challenge here 
is that the staff members of the Library System assume a formative role and that they are qualified for it. The former assumes that they have the necessary knowledge that allows response to the demands of the users and, at the same time, implies a motivation and a commitment to the challenge of the quality in the formation process.

\begin{abstract}
"as one has knowledge, one can speak with more precision about a determined subject...the library is not separate from the rest of the university. Everything is the university, everything that has to do with the quality of higher education" (Basic Sciences)

"how do our students learn?, how do they learn their own knowledge? Well I think that for us, the classmates of the Master's degree program, knowing this allows us to understand with more clarity the aims of Ágora Model." (Engineering)

"at this moment there are colleagues that are doing their Master's... I unfortunately for personal reasons, have not been able to do it, but I also know that I am obligated, or rather, my profession and work obligate me to stay current" (Ocean Sciences)
\end{abstract}

On the other hand, the necessity exists that all users (students, teachers and researchers) learn the tools that permit them to manage information in a way that transforms it into knowledge. In this sense, the users form a part of the library system not only in the utilization and evaluation of it, but also in its development.

\footnotetext{
"The learning is of each person, the library gives the resources and the tools, but it is each individual, each person that decides what she is going to learn and in what way she will utilize the resources that she has" (Basic Sciences)
}

\begin{abstract}
"The information can be data, but there is an implicit process while internalizing that information, as well as the way he generates his own knowledge from what he already knows..." (Engineering)
\end{abstract}

\begin{abstract}
"there is a moment in the course in which the professor says to me... I am going to leave you with the students so that you can teach them, for example we have a data base..." (Ocean Sciences)
\end{abstract}

The results of this study confirm two central dimensions around which organizational learning is oriented: a temporal dimension and a thematic dimension. The temporal dimension makes the organization look towards its past traditions and experience, or rather projects it towards the future. This temporal dimension is of special relevance from the organizational point of view, since the whole organization has a history and memory that connects it with the past and, in turn, it has a vision for the future of what it wants to become.

According to what was previously stated, we can say that the organization is constantly passing through this temporal dimension (past, present and future), reconstructing the past in order to give meaning to the present and to project itself into the future. The temporal perspective changes continuously according to the situation. However, although we have a tendency to orient ourselves towards one of two poles of this temporal dimension (past or future), it does not mean that the rest of the dimension remains excluded from our field of action.

\footnotetext{
"is we had a closer relationship, and I hope that in the future it will be like that, with the academic community..., that there is a relationship in this sense with intention of improving the quality of teaching" (Basic Sciences)
}

"I, taking that idea, thought that maybe it would be a good project to start with thinking of a digital journal that had as a central theme the university pedagogy at the Centre of Engineering and for that reason I have started to read, also I have started to ask myself what is the teaching of Engineering at the heart of the Faculty". (Engineering)

\begin{abstract}
"all of this new technology makes things different than they were before because the tools we count on today we didn't have a few years ago, and it is likely they will not be what we will have in another couple of years... we have had personnel and teamwork changes, the most immediate things; however it is difficult to predict the future because each day we cont on new tools, for example, three months ago I couldn't even imagine that I was going to have a laptop, I never thought I was going to bring it home and install it there" (Ocean Sciences)
\end{abstract}

The thematic dimension, according to the results of our research, puts the emphasis on levels of learning. In this dimension we can distinguish between two lines of arguments that, in turn, will determine two levels of learning: Level I learning and Level II learning. In the first focus of this thematic dimension (Level I) we find a type of learning of the techniques and procedures employed (learning how) that generally results in an improvement in abilities 
and organizational routines.

"In the way that one has contact with the material and with people, one realizes what it is that each person or determined area needs when they ask for something. One becomes familiar with the issues and knows, for example, what to recommend." (Basic Sciences)

"we who work in teams have to work like this, ...we have a good work team" (Engineering)

"to research what is email because I think it has affected the way of studying, because before it was always the photocopy and the notebook. Now I see many kids with their laptops, many come here to check their emails and also to get their homework." (Ocean Sciences)

In the second focus of this dimension (Level II) we encounter a type of learning of the premises and values that govern the operation of the organization, asking for the causes that originate determined problems (learning why).

"one has knowledge of things that are going on at other places, for example, I am referring to the university environment where one tends to compare. By comparing one realizes the strengths and also the weaknesses of what one sees" (Basic Sciences)

"It is also a classroom, in that way they have to respect it. It is a classroom that helps them to learn because everything that is technology in information and communication are everywhere today." (Engineering)

"this information changes everyday because one says: what is published today, will be outdated by tomorrow, so it is like a whirlwind, a vertiginous thing that comes at us. I hear it from professors who suddenly say to me: ...I am overloaded with things because I have so much information that I don't know what I am going to do, the information overwhelms you!" (Ocean Sciences)

\section{Discussion}

The results described here allow us to better understand the processes of information management, knowledge management and organizational learning management where a central aspect are the so-called "learning communities" (Brown and Duguid 1991), given that it is here where these three processes are fostered and articulated. Below (see Figure 1) is shown an integrated model of the process of management of information, knowledge management and management of organizational learning. The fundamental supposition of this model, which we have named the Ágora Model, is that the processes of management of information, of knowledge and of organizational learning, are intimately related, so that to develop these processes in an integrated way generates increasing performance for the organization. The following discussion explains how each one of these processes works in a university library system.

\section{Figure 1: Ágora Model}

The management of in-formation covers a large part of the work undertaken until now by university libraries. In it are included all the information resources, whether they be local or virtual, by means of which it becomes possible to satisfy the demands of the users of the service (Bauer 2001). The library as a place of information management centres its work in education as a direct activity and as a support activity to the teaching of the different disciplines. It creates new packages of knowledge and new tools to access information. It offers a physical environment that facilitates research and the collaboration of professors and students; and it offers access to some resources that constitute the necessary foundation for the establishment of learning communities (Bustos 1997; Teare et al. 2002).

The efficient management of in-formation attempts to ensure that the members of the learning community are competent in generating and transferring the knowledge acquired. Therefore, the quality of the in-formation defines an organizational culture and a level of knowledge where the users of the system are capable of understanding the situations in which they find themselves, enabling them to adapt to the situations, and resulting in a unique and pertinent response. We consider that the difference between the arrival of an Information Society and the development of a Knowledge Society lies in encouraging the emergence of learning communities and the generation of habits of effective communication (Duart and Sangrà 2000) that integrate thinking with doing and learning (Levine 2002).

The management of knowledge, according to the results of this study, would be the systematic 
process of finding, adding, selecting, organizing, distinguishing and presenting knowledge in such a way that the understanding of one or more areas of interest is improved. In other words, it attempts to generate and utilize spaces of human interaction (learning communities) that allow the development of the intangible assets that support the organization in the achievement of its objectives (Vignolo 1998). The creation of new knowledge is not only learning about other knowledge or the acquisition of external knowledge but is, basically, an internal construction or reconstruction that is given to the individual as much as it is to the organization in learning communities (Brown and Duguid 1991; Johnson et al. 2002), that plays an important role in the capacity of innovation on the part of the organization (Vignolo 1998; Perry-Smith and Shalley 2003).

In the context of universities, for an efficient management of knowledge, the strengthening of learning communities (intra- and interdepartmental networks) is important as well as the development of the inter-university networks that allow the exchange of generated knowledge (Bazillion and Braun 1998; Mamaghani 2002). When the unspoken is made explicit (by means of language), it is possible to reflect on the knowledge that the organization possesses and to that end on the organization's own identity (Brockmann and Anthony 2002; Fiol 2002). In terms of the process of organizational learning, this includes the modification of the cognitive structures of the organization as well as the behaviour of the organization. Only when the process of reflection has taken place and the modification of the cognitive structures has been produced as a consequence of a discontinuity in the history of the functioning of the organization, has an organizational learning occurred. A central element of the whole process is the change of identity itself of the organization (Nicolini and Meznar 1995; Ahumada 2001; Hatch and Schultz 2002).

The organizations that look to manage learning within the organization must develop an organizational culture in which it is possible to share, transfer and integrate knowledge between its members (Bor 2002). A large part of the learning of the "correct" standards of perceiving, thinking, feeling and behaving have as an aim an understanding of the events that occur within the organization and its environment. This would imply on the one hand that the culture can facilitate or hinder the process of organizational learning and, on the other hand, that this learning can precisely constitute a change in the already existing values and basic premises of the organization (Fowler 1998; Senge et al. 2002).

The Library as a learning organization (Duart and Sangrà 2000; Teare et al. 2002) must develop the ability to create, acquire and transform knowledge; it must constantly stimulate its members to increase their capacities. Learning organizations are provided with a network of shared information where empowerment is valued as the capacity to transform new knowledge into innovations, as shared knowledge and put into action (Robbins et al. 2002). The efficient management of information, knowledge and organizational learning consists of incorporating new knowledge, recovering other knowledge that is already possessed, integrating new knowledge with other already existing knowledge and, finally, filing the said knowledge for its subsequent use (DiBella et al. 1996; Davenport and Prusak 2001). All of these actions that are the basis of any type of learning imply the utilization of previous knowledge and the creation of new knowledge.

As for the role that the organizational culture plays in relation to the management of information, the knowledge and the organizational learning, we must emphasise the fact that it shapes the identity of the library system itself. On the other hand, the organizational culture creates an environment that considerably facilitates or obstructs the processes mentioned. In effect, the organizational culture, on having been understood as a set of invented premises, discovered or developed by a group, presupposes organizational learning. As the library faces its problems it learns to incorporate those premises that have turned out to be valid. This way, the staff learns a "correct" form to perceive, think and feel in relation to the organization and their environment.

Within this perspective of organizational culture, it seems relevant to consider that in an organization there coexist several subcultures 
that have many of the meanings (values and premises) that have been developed during its history. The organization learns to recognise its culture and subcultures, but also learns those processes by means of which this culture is constructed. In this way, the existing culture in a library system can be understood as the result of a negotiation, a product of the interaction of the different subcultures or learning communities. This suggests that the meanings generated by this interaction were not necessarily and entirely shared initially, but rather are the product of negotiation and dialogue within the organization.

\section{Conclusion}

Like every organization, Universities must take advantage of their competitive resources. They must know how to make intensive use of their knowledge when attempting to improve the processes of teaching and learning of their students to increase the generation of new knowledge through research and to optimise the transference of the said knowledge to the productive environment, by means of publication and technical assistance.

The results of the present study allow us to conclude that the processes of the management of knowledge, organizational learning and information are intimately linked. In fact it is only possible to obtain significant improvements in organizations if the organization acts to generate synergies between each one of these processes. An efficient management of information implies a requirement that the members of the learning community are competent in generating and transferring acquired knowledge. The quality of in-formation implies relying on the necessary information resources and on sufficient training to make intensive use of those resources. It is here that the teaching role assumed by staff members of the library system and the ability to meet the information needs of the library's users are of key importance.

The creation of new knowledge in communities of learning is, basically, an internal construction or reconstruction that is undertaken as much by the individual as by the organization. In the context of universities, for an efficient management of knowledge, the strengthening of learning communities (intra- and interdepartmental networks) is important as well as the configuration of inter-university networks that facilitate the exchange of the knowledge generated. Finally, the university library systems must develop the ability to create, acquire and transform knowledge, stimulating their staff to transform knowledge into innovations. In this respect, the efficient management of organizational learning implies not only the utilization of their previous knowledge but also the creation of new knowledge within the framework of what are termed "communities of learning."

\section{References}

Ahumada, L. 2001. Teoría y cambio en las organizaciones: Un acercamiento desde los modelos de aprendizaje organizacional \{Theory and change in organizations: An approach from the organizational learning models\}. Valparaíso, Chile: Ediciones Universitarias de Valparaíso.

Ahumada, L. 2002. El aprendizaje organizacional desde una perspectiva evolutiva y constructivista de la organización \{Organizational learning from an evolutive and constructivist point of view of the organization\}. Revista de Psicología - Universidad de Chile 11: 139-148.

Akeroid, J. 2001. The Management of Change in Electronic Libraries. IFLA Journal 27: 70-73.

Argote, L., McEvily, B., and Reagans, R. 2003. Managing knowledge in organizations: An integrative framework and review of emerging themes. Management Science 49: 571-582.

Ascorra, P. 2002. Acción organizacional y socioconstruccionismo \{Organizational action and socio-constructionism\}. Revista de Psicología Universidad de Chile 11: 165-173.

Barkema, H., Baum, J., and Mannix, E. 2002. Management challenges in a new time. Academy of Management Journal 45: 916-930.

Bauer, K. 2001. Resources for library assessment: tools for a new era. College $\mathcal{E}$ Research Libraries News 62: 12-14, 28.

Bazillion, R. J. and Braun, C. 1998. Academic libraries as high-tech gateways: a guide to design space decision. Chicago, IL: American Library Association.

Bor, K. 2002. Toward a theoretical framework for understanding the relationship between situated action and planned action models of behavior in information retrieval contexts: Contributions from phenomenology. Information Proccessing and 
Management 38: 613-626.

Brockmann, E., and Anthony, W. 2002. Tacit knowledge and strategic decision making. Group $\mathcal{E}$ Organization Management 27: 436-455.

Brown, J. and Duguid, P. 1991. Organizational learning and communities of practice: toward a unified view of working, learning, and innovation. Organization Science 2: 40-57.

Bustos, A. 1996. Gestión del proceso de cambio en la era de la información \{Change process management in the information era\}. Paper presented at CHILE INFO 96: Conferencia Internacional de Bibliotecarios de Educación Superior de América Latina y el Caribe, Santiago, Chile, 1996.

Bustos, A. 1997. Estrategia para la gestión de la información actual en la Universidad Austral de Chile \{Strategy for management of actual information in the Austral University of Chile\}. III Congreso de Bibliotecología and I Encuentro Internacional de Usuarios de CD-ROM, Universidad Austral de Chile, Valdivia, Chile, January 1997.

Cave, M. et al. 1997 The use of performance indicators in higher education: The challenge of the quality movement. $3^{\text {rd }}$ ed. London, UK: Jessica Kingsley.

Chia, R. 2000. Discourse analysis as organizational analysis. Organization 7: 513-518.

Davenport, T., and Prusak, L. 2001. Conocimiento en acción: Como las organizaciones manejan lo que saben \{Knowledge in action: How organizations manage what they know\}. Buenos Aires, Argentina: Pearson Education.

DiBella, AJ., Nevis, EC., and Gould, JM. 1996. Understanding organizations learning systems capability. Journal of Management Studies 33: 361-379.

Duart, J., and Sangrà, A. 2000. Aprender en la virtualidad \{To learn in virtuality\}. Barcelona, Spain: Gedisa.

Edwards, D., and Mercer, N. 1998. El conocimiento compartido \{The shared knowledge\}. Madrid, Spain: Paidós-MEC.

Fiol, CM. 2002. Capitalizing on paradox: the role of language in transforming organizational identities. Organization Science 13: 653-666.

Fowler, K. 1998. The University library as learning organization for innovation: an exploratory study. College and Research Libraries 59: 220-231.

Halliday, MA. 1994. An introduction to functional grammar. London, UK: Edward Arnold.

Harasim, L. et al. 2000. Redes de aprendizaje \{Learning networks\}. Barcelona, Spain: Gedisa.

Hatch, M., and Schultz, M. 2002. The dynamics of organizational identity. Human Relation 55: 9891018.

Herrera, R. 1998. Bases para el desarrollo cualitativo de la docencia universitaria \{Strategies for the qualitative development of university teaching\}. Santiago de Chile: Cinda.
International Organization for Standardization. 2000. Información y documentación. Indicadores de rendimiento Bibliotecario. (ISO 11620 - UNE 50137) \{Information and documentation. Indicators of librarian performance\}. Revista Española de Documentación Científica part I 22: 223-247; part II 22: $357-$.

Johnson, S. et al. 2002. Team development and group processes of virtual learning teams. Computers $\mathcal{E}$ Education 39: 379-393.

Karnoe, P. 1996. The social process of competence building. International Journal of Technology Management, Special Issue on Unlearning and Learning for Technological Innovation, 11: 770-789.

Kopp, J. 1998. Library consortia and information technology: The past, the present, the promise. Information Technology and Libraries 17(1): 7-12.

Levine, D. 2002. Thinking about doing: on learning from experience and the flight from thinking. Human Relations 55: 1251-1268.

Lindauer, BG. 1998. Defining and measuring the library's impact on campus-wide outcomes. College $\mathcal{E}$ Research Libraries 59 (6): 546-570.

Mamaghani, F. 2002. Information technology knowledge sharing using case-based reasoning. Information Systems Management 19: 13-20.

Nicolini, D., and Meznar, M. 1995. The social construction of organizational learning: conceptual and practical issues in the field. Human Relations 48: 727-746.

Nonaka, I., Takeuchi, H., and Umemoto, K. 1996. A theory of organizational knowledge creation. International Journal of Technology Management, Special Issue on Unlearning and Learning for Technological Innovation 11: 833-845.

Pérez, A. 2000. Bibliotecas y centros de documentación en un entorno virtual \{Libraries and document centers in a virtual environment\}. In: Duart, J., and Sangrà, A. Aprender en la virtualidad \{To learn in virtuality\}. Barcelona, Spain: Gedisa.

Perry-Smith, J., and Shalley, C. 2003. The social side of creativity: a static and dynamic social network perspective. Academy of Management Review 28: 89106.

Potter, J., and Wetherell, M. 1987. Discourse and social psychology. London: Sage.

Renkema, J. 2001. Manejo de la comunicación: Evaluación de la calidad del discurso institucional \{Managing communication: evaluation of the quality of institutional discourse\}. Revista Interamericana de Discurso y Sociedad 3: 11-33.

Robbins, T., Crino, M., and Fredendall, L. 2002. An integrative model of the empowerment process. Human Resource Management Review 12: 419-443.

Ruiz, J. 1996. Metodología de la investigación cualitativa \{Qualitative research methodology\}. Spain: 
Universidad de Deusto.

Senge, P., et al. 2002. La danza del cambio: Los retos que sostienen el impulso en organizaciones abiertas al aprendizaje (The change dance: the challenges that stimulate organizations open to learning \}. Barcelona, Spain: Norma.

Sisto, V. 2002. Teoría Psicológica en Acción: La Psicología Frente a las Consecuencias Psicológicas y Sociales de los Procesos de Flexibilización Laboral \{Psychological theory in action: psychology against the psychological consequences of the labour flexibilization processes\}. Psicoperspectivas Revista de Psicología Universidad Católica de Valparaíso 1: 111123.

Teare, R., Davies, D., and Sandelands, E. 2002. Organizaciones que aprenden y formación virtual \{Organizations that learn and virtual education\}. Barcelona, Spain: Gedisa.

Tsoukas, H., and Chia, R. 2002. On organizational becoming: rethinking organizational change. Organization Science 13: 567-582.

Van Dijk, TA. 2000. El discurso como interacción en la sociedad \{The discourse as interaction in society\}. In: Van Dijk, TA. El discurso como interacción social \{Discourse as social interaction\}. Barcelona, Spain: Gedisa.

Vergara, A., and Isaac, J. 1998. Tecnología de la comunicación e informática como apoyo a la docencia \{Communication and information technology as an aid to learning\}. Santiago de Chile: Cinda.

Vignolo, C. 1998. Zen en el arte de innovar: Hacia un nuevo paradigma de la innovación empresarial \{Zen in the art of innovation: Toward a new paradigm of business innovation\}. Estudios Públicos 70: 173-200.

Editorial history:

paper received 16 November 2005;

final version received 5 May 2006;

accepted 8 May 2006. 


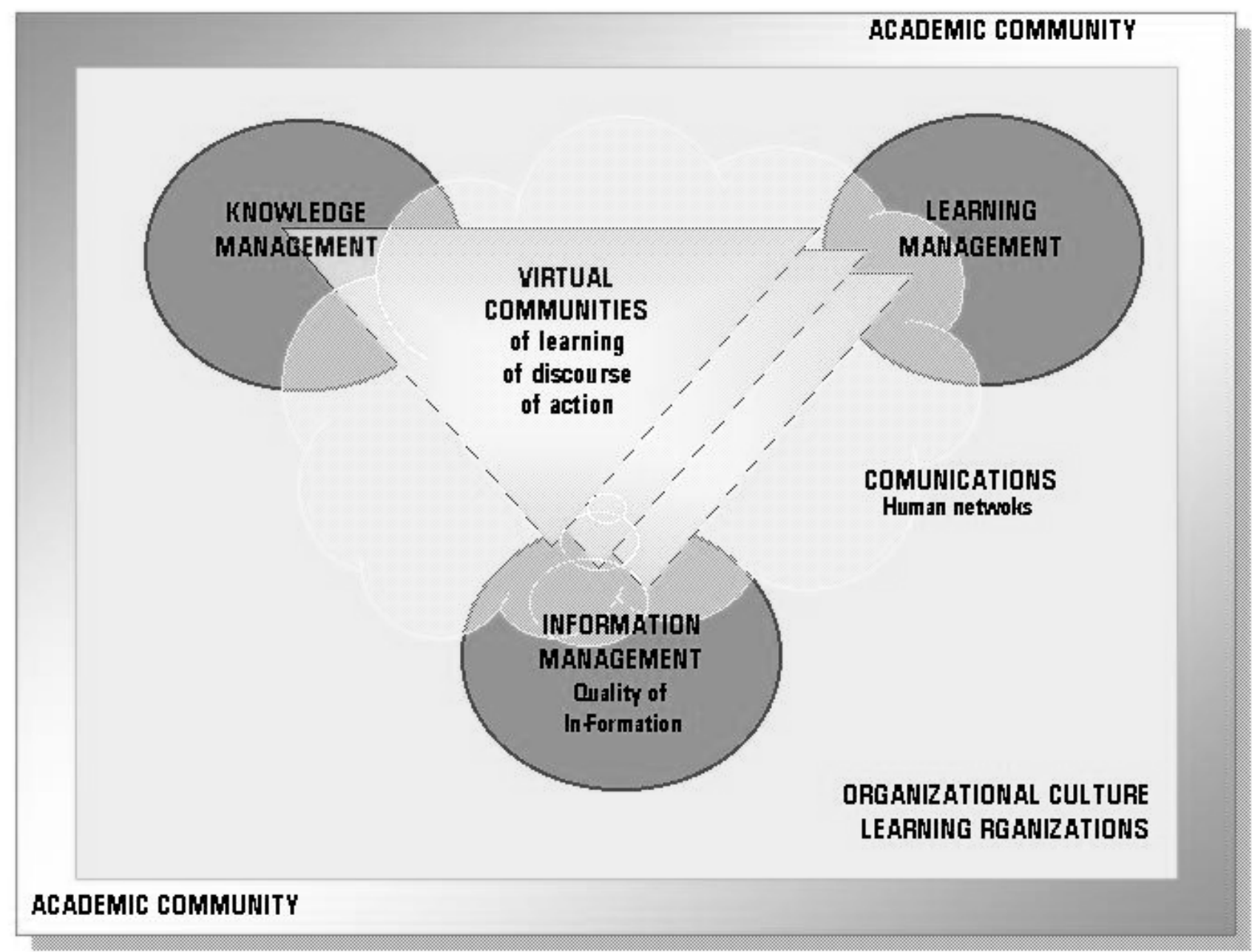

